\title{
The Integrated Critical Thinking Learning Model of Islamic Values
}

\author{
Muhammad Nasir \\ Muhammadiyah University of \\ Parepare \\ drshmnasirmpd@gmail.com
}

\author{
Buhaerah \\ Institut Agama Islam Negeri \\ Parepare \\ buhaerahstain@gmail.com
}

\author{
Nurhaedah \\ Muhammadiyah University of \\ Parepare \\ edaumpar@gmail.com
}

\begin{abstract}
The aimed of the study is to develop and designed to produce educational products in the form of critical thinking learning model that integrating the Islamic values. The purpose of this model it might be one of the guidelines for teachers or teaching staff to teach the learners by critical thinking that integrate of Islamic values. The problems of the study are 1) how does the character of the learning model for critical thinking integrated of Islamic values; 2) how to implement the learning model for critical thinking integrated of Islamic values; 3) how is the validity, and effectiveness of learning model for critical thinking? The study is including some results such as sync, social system, reaction principle, and support system. The syntax of this learning model is identifying and justifying concepts, solving problems, generalizing and analyzing algorithms, and making conclusions. The preliminary study result is shown some activities of learners that require a relatively long time, these are how learners respond to questions, provide comments, and assess the truth of the answer.
\end{abstract}

Keywords: learning, Model, Critical, Thinking, Islamic Values

\section{INTRODUCTION}

Today, a critical thinking is one of the goals of learning (Stacey, 2013; King \& Goodson, 2010; and Ghokhale, 2005) [1]. In line with the views of Gokhale (2005) and Paul \& Elder (2005), the critical thinking is now required by the learners to improve the quality of original intellectual thought and intellectual thinking. The government also stipulates that every learning manager equips the learners with the ability to think critically as future competencies (Kemdikbud, 2013) [2]. The exposure of critical thinking opinions is a mental activity to assess the truth of arguments, ask questions, and evaluate.Some researchers have developed a critical thinking model, those are; Marcut (2005), Watson \& Glaser (2008), and Bajracharya (2010). Marcut (2005) designed a model or pattern of critical thinking by creating conducive for learning conditions, such as; building communication in expressing ideas, listening and paying attention to friends who convey ideas, show interest in those ideas, work in groups to achieve the common goals [3], [2], [4].

Watson \& Glaser (2008) designed a thinking model that combines attitudes, knowledge, and skills to develop critical thinking skills[5], [6]. The Attitudes regarding efforts is to identify the problems and seek supporting evidence. Knowledge related to generalization process of abstraction, and valid conclusion, while the skills pertain how to apply attitude and knowledge. Bajracharya (2010) developed ABC model which is an acronym of the word anticipation, building knowledge and consolidation for critical thinking. Practice ABC model, among others; assigning learners to investigate, solve problems, work cooperatively, and express oral ideas derived from writing. Some results of this study are concluded that most people do not take the meaning of the thinking process lived. In line with the opinion of Mason, Burton, \& Stacey (2010) states that the initial knowledge that learners should have for critical thinking is not fully mastered [7], [8].

Some practices of critical thinking are integrated with Islamic values, among others; Aizikovitsh (2010) argues that critical thinking should contain ideas around good and expected. Ideas can be used as a reference to behave and doing it in the society or used as a measure of whether or not a phenomenon of action within the community itself. Gokhale (2005) argues that critical thinking is something that is believed to be true and embraced and made as a basic reference of individuals and the society in determining something that is considered good, true, valuable and valuable. Mason, Burton, \& Stacey (2010) argued that critical thinking is an individual personality that affects the selection of ways or actions that lead to the behavior and satisfaction in everyday life [9], [10].

Thus it can be concluded that the practice of critical thinking is integrated with Islamic values is the driving force in life, which gives meaning and validation to one's actions. Therefore, the value in each individual can color the personality of the group or the personality of the nation. Based on the critical thinking ability that integrating of Islamic values as a goal in learning it seems still far from reality. It can be seen from some preliminary research results show that critical thinking ability is still far from expectations; including; most or $80 \%$ of them do not know the steps to be taken to arrive at the answers accompanied by data and supporting 
evidence, as well as the reasons for how to obtain it.In addition, the learners have encountered difficulties in determining the true or false value of an argument and giving an explanation in their own words. One of the causes is the information that the learners know about making arguments, and how to communicate with it. The learning processes which support the development of critical thinking skills can be made by teaching the learners to make and construct arguments, especially on problem-solving, intellectual development, individual work, and group work[11], [12].

\section{METHOD}

The type of the study is a developmental research. The learning model to be developed it refers to the stages of model development proposed by Plomp (2013), such as 1) identification problem and needs analysis; 2) design and implementation; and 3) evaluation, while the quality criteria of the developed learning model that refers to Nieveen (2013) it is valid, practical, and effective. For more details see the flowchart.

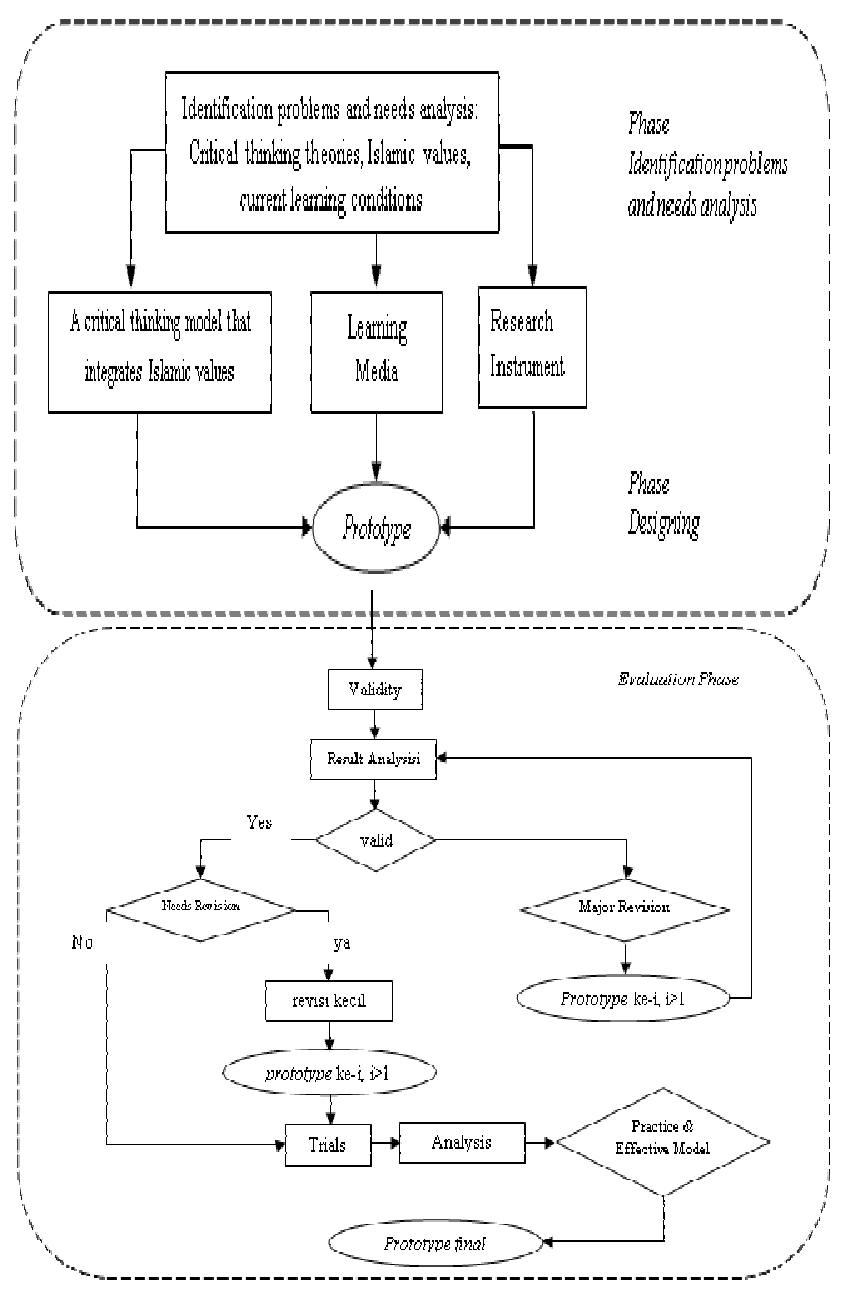

\section{RESULT}

The results that have been obtained during the development process are described based on the development procedure that has been taken which is composed of 3 stages; 1) identification problem and needs analysis; 2) design and implementation; and 3) evaluation. The first year development activities aretwo covering phases, such as phase 1 and phase 2, while the third stage of the plan implemented in the second year.

Phase 1 Identification Problem and Needs Analysis.

The results of identification problem and needs analysis of current learning conditions, especially the learning of developing critical thinking skills, either obtained through preliminary survey/research or through indirect observation which includes: the results of research theories and of results of results. The types of activities conducted in phase 1 such as 1) preliminary study results model, and 2) theory of critical thinking.

\section{Preliminary Study Result Model}

Bajracharya (2010) designed a model of learning that encourages a person to think critically called $\mathrm{ABC}$ model. The term $\mathrm{ABC}$ is an acronym of the word Anticipation, Building Knowledge, and Consolidation. The practice of $\mathrm{ABC}$ model is to develop a critical thinking among others, encouraging learners to conduct investigations by reading and writing, active problem solving and work cooperatively. As learners are instructed to draw a quadrilateral and discuss its properties. In this condition, all learners create a quadrilateral followed by the activity of thinking and sharing, and each learner comes forward to write down the results of his work.

\section{Theory of Critical Thinking}

The definition of critical thinking was used in this research is the intellectual process of explaining concepts, solving problems, and making decisions that can be trusted and believed to be true. This definition is examined from the opinions of Watson \& Glaser (2008), Hassoubah (2007), Walker (2006) [13]Krulik\& Rudnick (2003), Fisher (2001), Fowler (1996), Huitt (1994), and Halpern (1994).The practice of critical thinking on learning is consists of 3 components of reasoning, namely; standards of reasoning, reasoning, and intellectual reasoning. These components are the result of a review of the opinions of Paul \& Elder (2008). Likewise, the critical thinking aspects that are the focus of this research are: identifying and justifying concepts, solving problems, generalizing and analyzing algorithms. These aspects are the result of a study of opinions, among others [14], [15].

\section{Phase 2 Designed and Implementation}

Activities are undertaken at the design stage and modeling implements are defining the model book format, i.e. introduction, rational model development, supporting theories of learning models, learning models 
that develop critical thinking skills, and model implementation instructions, and bibliography. In the preliminary section described the potentials that exist in the learners who need to be maximized, so that learners can organize and control the way of learning. The rationale for the development of this model includes matters of primary consideration or basis for the importance of model development, current learning conditions, and research results that support the need for such development.

In this section discussing the theories supporting the learning model in describing several related theories, such as 1) learning theories, including; constructivism theory, learning theory of cognitive activity setting; and 2) critical thinking theory, among others; the notion of critical thinking, the components of critical thinking, the aspects of critical thinking, and measuring the ability to think critically.

In the implementation guide model is describing 4 things, and these are 1) the planning tasks, in this section, are outlined on things prepared for the learning model to take place practically and effectively. These include the formulation of objectives, selecting subject matter, and task analysis as outlined in the form of learning plan, teaching material, and student worksheet; 2) Interactive tasks, the syntax implementation consists of four stages, identify and justify concepts, solve problems, generalize and analyze algorithms, and conclusions.

At each stage in the syntax occurs the integration of objects learning mathematics and aspects of critical thinking; 3) learning environment and task management, this section included the task of the teacher to ensure the creation of a learning conducive environment and atmosphere, that is, the teacher should be in control of classroom management, such as how the learner speaks (communicates), regulates the use of time for each learning stage, the active involvement of learners especially in problem-solving, and overcoming the behavior of deviant learners; 4) evaluation, this section specifies the types and means of conducting assessment in learning, which is including traditional assessment (pencil and paper test), and performance appraisal (performance test).

\section{Identifying and Justifying the Concept}

In the previous review it has been explained that the indicator of critical thinking ability in the phase of identifying and justifying the concept is that learners choose or define the main concepts, then give explanations in their own complete, and true, words. The achievement of this indicator is done through reading activities and understanding. The description of activities contained in the BA. Further the interpreting and making assumptions, and then explain to his comrades.

This result enriches the previous findings, such as combines reading, and understanding of material descriptions, as well as social interactions for critical thinking, while the authors' findings of this study is more specific that is looking for information, then set the concepts that are considered important, and provide explanations with his own words.

\section{Problem Solving}

The indicator ability of critical thinking in the problem-solving phase of the PMBK model is to identify the problem (known, asked, the adequacy of elements) and make the mathematical model correctly, then the solution is correct. In this phase learners to think to make solutions or answers, and make ideas, express opinions or ideas. In addition, the learners work collaboratively to solve the problems. Working collaboratively is doing the collaborative work can improve learning outcomes, especially in terms of process and mastery of subject matter.

\section{Analyzing Algorithms and Generating}

A critical thinking indicators in phase is generalized and analyze algorithms are as follows; 1) learners are able to examine, correct, and explain every step of the problem solving of algorithm completely and correctly; and 2) learners are able to complete supporting data, and provide an explanation of how to obtain it completely and correctly.

The description of critical thinking ability in indicator 1 such as learners has been skilled at analyzing various solutions or answers based on the flow or procedure that has been done before and can contribute in the form of ideas, opinions or ideas. In this phase, analyzing the algorithm is considered useful by most learners, as a means to understand the work of self and others.

\section{CONCLUSION}

The process of developing in this learning model it refers to the theory of product development, such as problem identification and needs analysis, design and implementation, and evaluation.

1. The critical learning model that integrates Islamic values is a conceptual framework that can be used by teachers in developing critical thinking skills that integrate Islamic values.

2. Synonyms of this learning model, including; are: identifying and justifying concepts, solving problems, generalizing and analyzing algorithms, and making conclusions.

3. A result of the first study indicating some of the activities of learners that require a relatively long time, including how learners respond to questions, provide comments, and assess the truth of the answer.

\section{REFERENCES}

[1] P. Sikes, "Researching race and social justice in education. Essays in honor of Barry Troyna Response," Br. J. Educ. Psychol., 1998.

[2] W. Shi et al., "Development of an Instrument to Measure Higher Order Thinking Skills in Senior High School Mathematics Instruction," 
PYTHAGORAS J. Pendidik. Mat., 2017.

[3] G. Truman, "Researching primary teachers' work: Examining theory, policy and practice through interactionist ethnography," in Researching school experience : ethnographic studies of teaching and learning, 1999.

[4] T. Goodson-Espy, N. Naresh, and L. Poling, "Critical mathematics education: Extending the borders of mathematics teacher education," in Proceedings of the 38th annual meeting of the North American Chapter of the International Group for the Psychology of Mathematics Education, 2016.

[5] C. Thinking, “Critical Thinking," Library (Lond)., 1996.

[6] K. El Hassan and G. Madhum, "Validating the Watson Glaser Critical Thinking Appraisal," High. Educ., 2007.

[7] I. K. Bajracharya, "Influencing factors of critical thinking in classroom teaching," Educ. Q., 2010.

[8] J. M. Lodge, E. O'Connor, R. Shaw, and L. Burton, "Applying Cognitive Science to Critical Thinking among Higher Education Students," in The Palgrave Handbook of Critical Thinking in Higher Education, 2015.
[9] L. M. Burton, E. Bonilla-Silva, V. Ray, R. Buckelew, and E. Hordge Freeman, "Critical race theories, colorism, and the decade's research on families of color," Journal of Marriage and Family. 2010.

[10] C. B. Sheffield, "Promoting Critical Thinking in Higher Education: My Experiences as the Inaugural Eugene H. Fram Chair in Applied Critical Thinking at Rochester Institute of Technology," Topoi, 2018.

[11] R. Brandenburg et al., "Special Issue: Values education and holistic learning," J. Moral Educ., 2012.

[12] M. Irish et al., "Considering the role of semantic memory in episodic future thinking: evidence from semantic dementia.," Brain, 2012.

[13] C. Thomas and P. C. Walker, "A critical look at critical thinking," West. J. Black Stud., 1997.

[14] M. Tomasello et al., "A Comparison of Case Study and Traditional Teaching Methods for Improvement of Oral Communication and Critical-Thinking Skills.," Thinking, 2010. 